\title{
On Dialogue Teaching in Literature Course
}

\author{
DaJun Sun \\ Department. of Chinese and Media, Huainan Normal University, Huainan,232001, China \\ email: djsun@hnnu.edu.cn
}

Keywords: Literature courses; dialogue teaching; implementation

\begin{abstract}
Literature Teaching is an important aesthetic education method to experience language, enjoy image and taste sense. Dialogue Teaching is a comparatively suitable teaching method for the teachers of literature courses under the new teaching environment. This approach advocates new concept of knowledge, curriculum concept and teacher-student concept, breaking the closure and confrontation of all the teaching elements and will help to develop students' innovative spirit and practical ability.
\end{abstract}

\section{Introduction}

And now, with the new round prevailing trend of thought of technological pragmatism, a number of students who are hungry for quick success began to ignore and neglect the teaching of the humanities. How to break the traditional teaching methods in College Literature Course to train students in logical thinking ability, their creative literary image ability and writing skills and to develop the application-oriented talents to meet the needs of economics and social development is a currently real problem for the teachers of college literature courses to give a timely response and to resolve.

In modern society, dialogue, as an important way of life, is widely advocated by people. With the increasing development of network technology and popularization, as well as vigorous implementation of China's new basic education curriculum reform and quality education has become a consensus, to develop students' innovative spirit and practical ability has become the theme of classroom teaching. "Literature Curriculum Standards" points out: "in the process of Literature Teaching teachers and students should conduct equal dialogue." Thus, the dialogue theory is applied to literature teaching, it becomes the Literature Dialogue Teaching. Literary Dialogue Teaching emphasizes on teachers and students, teachers and teaching materials, student and student, students and teaching materials, the two-way communication of democracy and equality of self-dialogue of teacher- student, helps to improve the quality of teaching and students' innovative spirit and practical ability.

\section{The Theoretical basis of Literary Dialogue Teaching}

In recent years, with the deepening research on it, Literary Dialogue Teaching has been attracted increasing domestic and foreign experts and scholars' attention. Modern Dialogue Theory holds that the relationship between authors and readers reflects the spirit linkages between people and establishes a dialogue-exchange relation between them. This relationship is two-way, interactive and interdependent conditions; Modern Constructivism views that learning is the process of learner active construction of meaning and the intake of learners in the learning and reorganization of the transformation of knowledge. Modern curriculum theory holds curriculum is the process that teachers and students to explore the unknown. This process contains extension of the concept of thinking, change and development through the understanding of teachers and students exploring the field of development. Reception Aesthetics ,represented by German scholars Jauss. Iser, holds the view that the meaning of work is only can be achieved the active reader who communicates with the works and dialogues with them by reading, which is the interactive product of the works and readers. Mikhail Bakhtin, a Soviet Union thinker of the 20th century, said: dialogue is a way of human existence which 
means to engage in dialogue exchanges. This kind of speech exchange is an inherent dialogue relationship.

These theories indicate that education is building up through the positive teacher-student interaction; learning is the activities of constructing knowledge through students' active participation and dialogue with teachers and textbooks on the base of their experience, Specific to the teaching of literature, Which is the activity to explore the language charm, comprehend literary sense and cultivate the innovative spirit and practical ability with the literature image of ideas between teachers and students.

\section{The Main Features of the Literary Dialogue Teaching}

Literary Dialogue Teaching is not only an important aesthetic education method to experience language, enjoy image and taste sense, but also the dynamic process of thinking collision and spiritual and soul communication between teachers and students. In Literary Dialogue Teaching this process has three basic characteristics:

One is equality. For a long time, literature teaching is often teacher-led instruction and one-man-like spoon-feeding teaching. Students have to passively hear the teaching under unequal relationship. The aim of Literary Dialogue Teaching is to establish a kind of interaction relation, which emphasizes both teachers and students have the equality in teaching activities. This equality means the equality of personality and academic ideas; this equality also reflects mutual respect for each other's unique individuality, freedom and lasting exchange of views between the two sides, open to the spirit acceptance for each other, to achieve the spirit of echo and share different the literary experience.

Second is openness. Elegant Si Bayles said: The dialog is the truth bright and thought's realization. The dialog takes the human and the environment as a content, may discover that thinks of the thing logic and the existence significance. In literature dialog teaching activity, because interlocutor's knowledge, the life background are different, the literature text significance contains and the uncertainty, adds the reality society's enormous richness again, the dialog has the big difference inevitably, this kind of difference may cause the interlocutor to share each other's ponder, the experience and the knowledge, communicates, the mutual influence, to supplement, the one learns by teaching mutually.

(3)Third is interactive. In the literature dialog teaching, teachers and students both sides talk the process is between actually teachers and students, in the experience shares realizes the interactive process, what between each other carries on is the positive communication and the cooperation, the understanding and the self-construction. It did not look like past monologue type teaching, paid great attention the knowledge the duplication and the reappearance, but unceasingly was restructuring and the renewal knowledge structure, paid great attention the knowledge the production, it could inspire the interlocutor to have the unique mentality, the novel viewpoint to the literature explanation comprehension, caused the literature classroom to stimulate the bigger study interest in the thought collision, vital and charm.

\section{The Approach of the Literary Dialogue Teaching Realization}

The Literature Dialog Teaching initiates the new knowledge view, the curriculum view, the teachers and students view, has broken all teaching essential factor seal and the opposition condition. It mainly realizes by the way of the five aspects: the teacher and the student, the teacher and the teaching material, the student and the teaching material, the student and the student, teachers' and students' self-dialog.

The Dialog between the Teacher and the Student.In the traditional literature teaching activities a teacher nearly takes care of everything and the monologue substituted student's ponder. The teacher appeared by luminary's posture and the student did not have the independency. The dialog between the teacher and the student only pauses on the surface of the language and has little chance to penetrate into each other's deep thoughts. In the literature dialog teaching, between the teacher and 
the student there is no longer that kind of the host - visitor relation which the teacher always instills knowledge into the students by spoon-feeding, and the teacher transforms by the initiator as the promoter, transforms by the superintendent as the guide, forms the kind of democratic, equal and caring psychic dialog contact relations. In the dialog, both sides can appreciate each other and carry on the sincere communication and exchange. The teacher explains the literary work significance to the student and the student speaks freely about the literature text esthetic implication, the esthetic value's feeling and the assurance. The teacher guides the student to know the literary concept mixed with the author's ideas, the text, the society and many other factors correctly, trains the student to establish the feeling, the understanding, to utilize, the creation interest and ability. Through such kind of dialog in the classroom, they stimulate each other to realize each other spirit meet, the mind sympathetic chord, life significance tracking down mutually, thus to obtain the spiritual sublimation and cause the literature classroom to be vital and attractive.

The Dialog between the Teacher and the Teaching Materials.In the traditional literature teaching, the school and the teacher often regard the teaching material as "the Holy Bible" and think: so long as the teacher teaches the teaching material content in the stipulation time, he or she has completed the teaching duty. That the student studies the whole textbook has completed the study task. But in the literature dialog teaching, the authority of teaching material is basically dispelled, and the teaching material only provides one kind of reference for study, the teacher cannot absolutely satisfy one at hand. Certainly, before entering the classroom, the teacher must first depend on the teaching material and has a thorough understanding of it. Simultaneously the teacher must penetrate with the teaching material world related to the subject and major to form his own esthetic judgment and the esthetic experience, finally to form his own understanding (viewpoint) by the comparative analysis and absorbing manager. This kind of understanding (viewpoint) should manifest a university teacher's individual emotion, experience and wisdom, simultaneously also absorb all the families theory, seek marrow of all families and cover the viewpoints from all previous dynasties literary world to some contemporary authoritative scholar's. Because of the influences of different time, cultural context, home environment, education experience and education idea, in the dialog with the teaching material, the teacher's individual feeling strength, comprehension strength, imagination and creativity will be out of the ordinary and has rich originality. It will attract the teacher to explore and discovery literature world splendor and wonder and thus will form also the teacher individual teaching style to be characteristic.

Student and Teaching Material's Dialog.In the traditional literature teaching, the teaching material is the main study tool. The teacher must teach students systematically basing on teaching material's knowledge. But in the literature dialog teaching, the literature teaching material already is not only the knowledge and memory understood and repeated in the traditional significance, but also more important to the understanding and exchange, feeling and experience to it. The student faces the teaching material and transfers the existing knowledge reserve and the experience from the multiple perspectives and multi-level to realize the significance which the teaching material covers and to blend with it. What the contemporary education theory stressed is the independence, the cooperation, the inquisition-like study, and requests students not to satisfy the only teaching material in the hand and teacher's explanation, should be familiar with teaching material, inquire into it, integrate it, to carry on the independent study, to be active to inquire into, grouping cooperation, thus to gain more knowledge and obtain more comprehension.

Student and Student's Dialog.In the traditional classroom teaching involves little crosswise relation among the students, which is a long-standing phenomenon in the literature teaching. The literature dialog teaching even pays more great attention to their thought exchange, knowledge sharing and emotional education. In literature classroom dialog, because of their different life experience, state-of-art, comprehension ability and the esthetic appeal, in the learning process their sensation to the text-spoken language, image understanding and significance comprehension can be different. Therefore, through the forms of discussion class, debate class, deliberation class and so on, the teacher displays the appraisal function of guide and summary, gives the students the classroom leading power, encourages students to make bold speeches, to speak freely, to state views and lets the 
students unceasingly enhance in mutual exchanges studies and understand the text significance, thus to achieve the temperance spoken language, to make the individuality widely known, to realize the effect of the true feelings from experience, to transfer the student positive initiative study, sharing knowledge, the emotion, the significance and thus to form the literature classroom spirited dynamic aspect.

Teachers' Self-dialog and Students' Self-dialog. Self-dialog, namely, is that one dialogs to oneself, which is the dialog high-level shape. The literature teaching's essence is that the teachers and students talk to their self-thoughts integrated essential factor, their own knowledge, emotion and wisdom basing on the literature curriculum. This kind of self-dialog is the understanding to the innovation and distinct significance of the literature article, is the self-reconsideration to the literary culture teaching, through this kind of reconsideration the teachers and students can discover and correct the mistake unceasingly, adjust teaching and study's strategy promptly, transform the knowledge learnt to their own ability and quality, realize the self-liberation, the self-promotion and the self-development truly and achieve "the spirit sets up the human" finally.

\section{Conclusion}

Literature Teaching is an important aesthetic education method to experience language, enjoy image and taste sense. Dialogue Teaching is a comparatively suitable teaching method for the teachers of literature courses under the new teaching environment. This approach advocates new concept of knowledge, curriculum concept and teacher-student concept, breaking the closure and confrontation of all the teaching elements and will help to develop students' innovative spirit and practical ability.

\section{Acknowledgement}

This study is one of research achievements of Study on New Rural Construction and Ecological Protection of Traditional Village Culture supported by Anhui Provincial Academy of Social Sciences Plan Project (AHSK11-12D292), and one of research achievements of Anhui Huagu Opera Art Style Research from the View of Regional Culture supported by Anhui Provincial Humanities and Social Sciences Research for Universities (SK2012116).

\section{References}

[1]Cai Chun, Hu Zhongping. From "Monologue" to Dialogue, Educational Research[J], 2002(2):49-52.

[2]Zhong Qinquan. Dialogue and Discourse: The transition of Teaching Norms[J]. Educational Research, 2002(3):33-39.

[3]Liu Qingchang.An Initial Discussion on Dialogue Teaching[J]. Educational Research, 2001(11):65-69.

[4]Li Baoqing, Li Cuimei. An Initial Discussion on Dialogue Teaching[J].Contemporary Educational Science, 2004,(6):21-23.

[5]Xiao Zhengde. A Decade of Research on Dialogue Teaching in China[J]. Review and Reflection, Higher Education Research , 2006(4):68-73.

[6]Zhang Zengtian, Jin Yule. On Dialogue Teaching under the Background of New Curriculum[J]. Journal of Southwest China Normal University (Humanities and Social Sciences Edition) , 2004(9):77-81.

[7]Ba Hejin. Discourse. Dialogue and Humanities[M]. Shijiazhuang: Hebei Educational Press , 1998.113.

[8]Liu Yaoming. From Teaching Dialogue to Dialogue[J]. Shanghai Educational Science and Research, 2005(2):62-65. 